\title{
Bioremoval of Acephate by biofilm-forming Enterobacter cloacae- VITDAJ8 in a vertical packed bed biofilm bioreactor
}

\author{
Dipti Mayee Dash, Ankita Itusha, Jabez Osborne $W^{*}$ \\ Department of Biosciences, School of Bio Sciences and Technology, Vellore Institute of Technology, Vellore - 632014, India \\ Received 20th September 2019 / Accepted 21st September 2020
}

\begin{abstract}
Organophosphorus (OP) pesticides are widely used due to their specific chemical properties and broad spectrum insecticidal activity. Accumulation of OP residues in various targeted and nontargeted environmental sites have increased the risk of biomagnifications thereby rendering serious threat to human health and the environment. Hence, the present study is primarily focused on the effective removal of Acephate (ACP) from aqueous solution. Bacteria isolated from the agricultural field and tannery effluent were screened based on their tolerance against two OP pesticides. The pesticide-resistant strains were further screened for biofilm formation and EPS production under ACP stress. Isolate VITDAJ8 exhibited highest pesticide tolerance against ACP, excellent biofilm formation and EPS production ability. Molecular characterization of VITDAJ8 by 16S rRNA gene sequencing revealed the isolate to be the closest neighbor of Enterobacter cloacae (Accession no. KP305912). A bench-scale vertical packed bed biofilm bioreactor was designed for the bioremoval of OP pesticides. Groundnut shells with a bed height of $10 \mathrm{~cm}$ were used as substrate with biofilm formed by VITDAJ8. The biosorption of ACP from the aqueous solution was monitored using UV-Vis spectrophotometer and HPLC and maximum ACP bioremoval up to $86 \%$ was achieved within 90 minutes of reaction time. Removal of ACP using groundnut shells without biofilm support was comparatively less efficient. The equilibrium adsorption study revealed the process to be the best fit for Langmuir isotherm modeling with maximum adsorption up to $235 \mathrm{mg} \mathrm{L}^{-1}$ and the kinetics of biosorption was found to be fitting well with the second-order kinetic model.
\end{abstract}

Keywords: Organophosphorus, biofilm, Enterobacter cloacae, biosorption, bioreactor

\section{INTRODUCTION}

Organophosphorus (OP) is one of the most predominantly used classes of pesticide accounting $34 \%$ of global pesticide consumption (Singh and Walker, 2006). OP pesticides with three major structural variations of $\mathrm{OP}$ compounds such as phosphate, phosphorothioate, and phosphorodithioate are being used widely (Kwong, 2002). The chemical structure of OP pesticide contains a chemically reactive organophosphorus (OP) compound, which is a derivative of phosphoric, phosphonic, phosphinic, or thiophosphoric acids with a central phosphorus atom. The central $\mathrm{P}$ atom is either linked via a single or double bond to $\mathrm{O}, \mathrm{N}$, or $\mathrm{S}$ atom in the form of esters, amides, or thiols. The OP compound is generally coupled with two organic functional groups and an additional side chain of cyanide, thiocyanate, or phenoxy (OrtizHernández et al. 2013; Kumar et al. 2018). Monocrotophos (dimethyl [(E)-4-(methylamino)4-oxobut-2-en-2-yl] phosphate), an organophosphate insecticide, and Acephate (N-

*Author for correspondence: Jabez Osborne W, Department of Biosciences, School of Bio Sciences and Technology, Vellore Institute of Technology, Vellore-632014, India. Email - jabez.vit@gmail.com 
[methoxy(methylsulfanyl)phosphoryl]acetamide), an organothiophosphate insecticide are predominantly used in agriculture. The incalculable application of OPs in the past few decades has become one of the major anthropogenic sources of pollution. OP pesticides are widely used in agriculture due to low cost, easy availability, and a broad spectrum of insecticidal activity. The direct and indirect release of OP pesticides into to environment has caused their accumulation in various target and non-target sites. Discharge of toxic effluents generated from pesticide manufacturing industries into water bodies has become one of the major concerns in environmental safety. Therefore, various physical and chemical treatment methods implemented for the remediation of OP contaminated water include wet oxidation, electrochemical oxidation (Aimer et al., 2017; Aimer et al., 2019), photocatalytic oxidation (Petsas and Vagi, 2018), fumigation (Sintuya et al., 2018), etc.

Biological methods are more efficient, reliable, cost-effective and eco-friendly as compared to physical and chemical treatments. Indigenous microbial communities bear the potential to eradicate toxic pollutants from the environment naturally. Nonetheless, the natural attenuation process sometimes is hindered by less abundance of the indigenous microbial community, lack of access to the contaminated areas and nutrient deficiency (De Lipthay et al., 2003). Therefore, several non-conventional techniques have been implemented for the mitigation of pesticide pollution which introduced the application of bioreactor systems where microbes especially bacteria are being used in the form of cell suspension, biofilm or in immobilized forms. Stirred tank bioreactors (STBR) and moving bed biofilm reactors (MBBR) have shown promising results in the removal of wide range of contaminants (González et al., 2006; Cuci and Taşkın, 2020; Rodríguez-Castillo et al., 2019; Mavriou et al., 2020). However, another hybrid bioreactor system that is attracting more interest in the biodegradation of toxic recalcitrants is packed-bed biofilm bioreactor. Studies have proven that a packed-bed bioreactor system not only protects the microbial cells from stressful conditions but also accelerate the biodegradation process. It provides high productivity and stability as it can be operated at high volumetric active biomass concentrations that result in small reactor volumes, thereby, have an enhanced ability to perform well at low-influent substrate concentrations without the need to separate the biomass and the treated effluent (Ercan and Demirci, 2015; Alfonso-Gordillo et al., 2016). Packed-bed bioreactors also work efficiently in case of slow growing microbes as the cells are used either in immobilized form or in the form of surface-attached biofilms (Nicolella et al., 2000). Besides, biofilm-forming, motile microorganisms exhibit more versatility in the degradation of contaminants than that of the free-living planktonic microbes (Edwards and Kjellerup, 2013). Biofilm forming communities of bacteria are involved in the secretion of soluble or insoluble polymeric substances which in turn develops a matrix of exopolysaccharides or extracellular polymers (EPS). Due to the specific structural, biochemical, and physiological properties these 3-dimensional biofilms matrixes play a prime role in the degradation of organic pollutants and oxidation of toxic heavy metals (Singh et al., 2006; Breugelmans et al., 2010). Studies have shown the contribution laid by bacterial biofilm in the bioremoval of heavy metals, dyes, pesticides and other organic and inorganic pollutants (Modin et al., 2008; Pani et al. 2017; Derakhshan et al. 2018). Dash and Osborne (2020) in a recent study reported biofilm based bioremoval of OP pesticides quinalphos and profenofos using a vertical-flow packed bed biofilm (VFPBB) bioreactor with mushroom (Agaricus bisporus) as biofilm carrier exhibited efficient biodegradation potential. Many studies have also been conducted in the utilization of biodegradable polymers, biodegradable meal box (BMB), gravels, groundnut shell, coconut husk, cucumber peels, etc., as biofilm carriers (Chandran and Das, 2011; Shen et al. 2013; Li et al. 2016; Pani et al. 2017). Groundnut shells however, an organic agro waste product has been prominently used as biofilm carrier in the biofiltration of wastewater in various column based studies due to high porosity and function as carbon source for bacteria attached to their surface (Rout et al., 2017). Reports have shown convincing results for biofilm-based biosorption of xenobiotics especially heavy metals from contaminated water (Chandran and Das 2011; Pani et al., 2017). 
Hence, the present study investigated the bioremoval of MCP and ACP pesticides from artificially contaminated water using a costeffective, bench-scale vertical packed bed biofilm bioreactor using groundnut shell as the substrate for biofilm formation.

\section{MATERIALS AND METHODS}

\section{Soil sampling and chemical reagents}

Commercial grade Monocrotophos (MCP) and Acephate (ACP) were procured from agrochemical shop in Vellore, Tamil Nadu. Stock solutions of $50,000 \mathrm{mg} \mathrm{L}^{-1}$ for both the pesticides were prepared in sterile d. $\mathrm{H}_{2} \mathrm{O}$. Minimal salts media (MSM) $\left[\left(\mathrm{Na}_{2} \mathrm{HPO}_{4}, 5.8 ; \mathrm{MgSO}_{4}, 0.25\right.\right.$; $\mathrm{NH}_{4} \mathrm{Cl}, 1 ; \mathrm{NaCl}, 0.5 ; \mathrm{KH}_{2} \mathrm{PO}_{4}, 3.0$ in $\left.\mathrm{g} \mathrm{L}^{-1}\right), \mathrm{pH}-$ 7.0] was used as growth medium for enrichment, isolation and biodegradation experiments. Nutrient broth (NB) medium was used for qualitative and quantitative analysis. Soil samples were collected from two distinct locations in Ranipet $\left(12.928303^{\circ} \mathrm{N}, 79.332485^{\circ} \mathrm{E}\right)$ India, by the random sampling procedure. Contaminated soil was collected from the surroundings of tannery industries and rhizosphere soil was collected from wetland paddy field with a minimum distance of approximately 50 -meter.

\section{Isolation of pesticide-resistant bacteria by enrichment culture}

Soil samples collected from different locations were mixed and $5 \mathrm{~g}$ of the soil mixture was added to individual flasks containing $100 \mathrm{ml}$ of MSM supplemented with $250 \mathrm{mg} \mathrm{L}^{-1}$ of MCP and ACP. The soil enrichment was incubated in an orbital shaker $\left(120 \mathrm{rpm}, 28 \pm 2^{\circ} \mathrm{C}\right)$ for 5 days. Bacterial growth was monitored regularly by serial dilution and plating techniques. The morphologically distinct bacterial colonies were picked and were maintained in MSM agar supplemented with 200 $m g \mathrm{~L}^{-1}$ of MCP and ACP.

\section{Screening for effective bacterial strain}

Maximum tolerable concentration (MTC) assay

Bacterial pesticide resistance was evaluated by MTC assay. Isolates were inoculated into MSM supplemented with MCP and ACP concentration ranging from $200-2000 \mathrm{mg} \mathrm{L}^{-1}$ and incubated for
$24 \mathrm{~h}$ in an orbital shaker $\left(120 \mathrm{rpm}, 28 \pm 2^{\circ} \mathrm{C}\right)$. Cell viability was checked by drop plate technique (Bhalerao and Puranik, 2007).

\section{Detection and quantification of bacterial biofilm}

The isolates were inoculated into test tubes containing $10 \mathrm{ml}$ of sterile Tryptic soy broth and incubated for $24 \mathrm{~h}$ in a rotary shaker at $120 \mathrm{rpm}$ followed by incubation at the static condition for another $24 \mathrm{~h}$ at $28 \pm 2^{\circ} \mathrm{C}$. Development of biofilm by each isolate was evaluated by crystal violet staining as described by De Rossi et al. (2007). Biofilm forming E. coli strain was used as the positive control and uninoculated medium served as the negative control. Formation of visible film lining on the wall of the test tubes was examined and the strength of biofilm formed by the isolates was categorized as strong, moderate, weak and negative. The strong biofilm-forming bacterial strains were further subjected to the quantitative analysis of biofilm formation in a 96-well round bottom PVC microtiter plate. The bacterial strains were inoculated into media supplemented with various concentrations of ACP and MCP (150 $\left.600 \mathrm{mg} \mathrm{L}^{-1}\right)$ to investigate the effect of pesticide on biofilm formation. Inoculums $(200 \mu \mathrm{l})$ with and without pesticide treatment was added into the wells of the microtiter plate. Uninoculated MSM with and without supplementation of pesticides served as control. The microtiter plate was incubated for $48 \mathrm{~h}$ under static condition. Biofilm formed in the microtiter plate was extracted and quantified at $570 \mathrm{~nm}$. All the experiments were performed in triplicates. The specific biofilm formation by each bacterial strain was calculated using the formula,

$$
\mathrm{SBF}=\mathrm{AB}-\mathrm{CW} / \mathrm{G}
$$

Where $\mathrm{AB}=\mathrm{OD}_{570 \mathrm{~nm}}$ of stained biofilm, $\mathrm{CW}=$ $\mathrm{OD}_{570 \mathrm{~nm}}$ of uninoculated media (control) and $\mathrm{G}=$ $\mathrm{OD}_{620 \mathrm{~nm}}$ of culture broth (Christensen et al., 1985).

\section{Extraction and quantification of EPS}

The strong biofilm producing bacterial strains were further assessed for their ability to produce EPS under pesticide stressed condition. Isolates were inoculated into NB supplemented with various concentrations of ACP and MCP (150 $\left.600 \mathrm{mg} \mathrm{L}^{-1}\right)$ and incubated for $48 \mathrm{~h}$ in an orbital shaker at $150 \mathrm{rpm}$. Media without pesticide 
treatment was used to determine the effect of pesticide on EPS production. The experiments were performed in triplicates and the total EPS produced by each isolate was estimated by phenol-sulphuric acid method using glucose standard and were run at $490 \mathrm{~nm}$ (Dubois et al., 1956).

\section{Identification of effective strain}

Morphology of the bacterial isolated grown on MSM agar was observed and the biochemical characteristics were assessed by performing standard biochemical tests such as indole, methyl red, Voges Proskaur, citrate utilization, triple sugar iron, oxidase and catalase tests as described by Cappuccino and Sherman (1992). The molecular characterization of the effective bacterial strain was performed by $16 \mathrm{~S}$ rRNA gene sequencing using the universal primers $27 \mathrm{~F}$ (5' AGAGTTTGATCCTGGCTCAG-3') and 1492R (5'-GGTTACCTTGTTACGACT'T-3'). Bacterial DNA was extracted and the $16 \mathrm{~S}$ rRNA gene sequence was determined by fluorescent dye terminator method using the sequencing kit (ABI Prism Big dye terminator cycle sequencing ready reaction kit v.3.1). Products were allowed to run on an ABI13730XL capillary DNA sequencer (ABI Prism 310 genetic analyzer, Tokyo, Japan). The aligned sequences were computed using ClustalW software and sequence homologies were compared using BLAST. Multiple alignments were performed and the phylogenetic tree was constructed by the neighbor-joining method using the default parameters of MEGA4 (Tamura et al., 2007) and bootstrapped using 1000 bootstrap trials.

\section{Bioremoval of ACP in vertical packed bed bioreactor \\ Construction of bioreactor}

A cost-effective continuous-flow vertical packed bed bench-scale bioreactor (height $-28 \mathrm{~cm}$, diameter $-7 \mathrm{~cm}$ ) was designed using waste polyethylene bottles (Figure 1). The bioreactor setup comprised of three distinctive parts such as the lower inoculums reservoir, the substrate chamber in the middle and the sprinkler on top for even distribution of the sorbet onto the substrates. The reactor consisted of an inlet on top of the reactor and an outlet port along with a valve provided at the bottom for withdrawal of the sample. The bioreactor was run with the help of an electric motor for the continuous circulation of sorbet. The flow rate was maintained at $50 \mathrm{ml}$ $\mathrm{min}^{-1}$. Groundnut shells were used as substrate to facilitate waste management (Pani et al., 2017).

\section{Substrate preparation and Development of biofilm}

Groundnut shells were thoroughly washed with distilled water and dried intermittently in a hot air oven for $24 \mathrm{~h}$ at $45^{\circ} \mathrm{C}$. Shells were further cut in to $1 \mathrm{~cm}^{2}$ sized pieces. Autoclaved groundnut shells were placed in the substrate chamber to obtain a bed height of $10 \mathrm{~cm}$. MSM $(500 \mathrm{ml})$ augmented with the effective strain was run through the bioreactor for $48 \mathrm{~h}$ for the development of biofilm on the groundnut shells. The substrates were kept immersed in the bacterial culture medium for another $24 \mathrm{~h}$ to enhance the attachment and stability of biofilm. Biofilm formed on the substrate was estimated by dilution plate count technique where $1 \mathrm{~cm}^{2}$ portion of the groundnut shell was suspended into sterile distilled water and the biomass was dissolved by vigorously mixing.

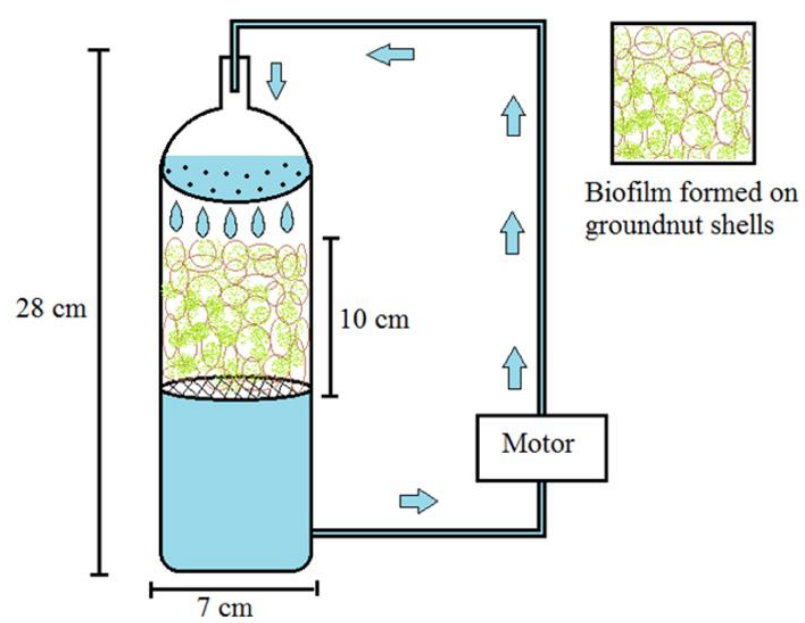

Figure 1. Hypothetical design of bench-scale vertical packed bed biofilm bioreactor.

\section{Bioremoval of $A C P$}

The aqueous solution of ACP with $300 \mathrm{mg} \mathrm{L}^{-1}$ was run through the bioreactor for $90 \mathrm{~min}$ after successful development of biofilm. Treated samples were withdrawn at a regular interval of 10 mins and ACP biosorption by bacterial biofilm was monitored using a $U V$-visible spectrophotometer at $216 \mathrm{~nm}$ and HPLC (Waters 1525 binary HPLC pump, Milford, USA) using Symmetry C18 reverse-phase column (Waters 5 
$\mathrm{mm}, 4.6 \mathrm{~mm}$ X $150 \mathrm{~mm})$. The biosorption potential of groundnut shells without biofilm support was also evaluated. The bioremoval \% was calculated using the formula,

$$
\text { Bioremoval }(\%)=\frac{\mathrm{C}_{\mathrm{In}}-\mathrm{C}_{\text {out }}}{\mathrm{C}_{\mathrm{In}}} \times 100
$$

Where $C_{\text {in }}$ is the initial concentration of ACP at time $t_{0}$ and $\mathrm{C}_{\text {out }}$ is the concentration of ACP in the aqueous solution at time $t$.

\section{Adsorption isotherm and kinetic studies}

The equilibrium data were analyzed with Langmuir and Freundlich adsorption isotherm models to characterize the mode of interaction between the pesticide molecules and the adsorbent surface. Langmuir isotherm kinetics The Langmuir isotherm is based on assumptions that the maximum adsorption corresponds to a saturated monolayer of sorbate molecule on the adsorbent surface. The isotherms plotted are described by linear form of the Langmuir isotherm equation $\boldsymbol{C}_{\boldsymbol{e}} / \boldsymbol{Q}_{\boldsymbol{e}}=\mathbf{1} / \boldsymbol{Q}^{\mathbf{0}} \boldsymbol{b}+\boldsymbol{C}_{\boldsymbol{e}} / \boldsymbol{Q}^{0}$, where $\mathrm{C}_{\mathrm{e}}$ is the equilibrium concentration $(\mathrm{mg} / \mathrm{g}), \mathrm{Q}_{\mathrm{e}}$ is the amount of pesticide adsorbed at equilibrium $(\mathrm{mg} / \mathrm{g}), \mathrm{Q}^{0}$ and $\mathrm{b}$ are the Langmuir constants related to adsorption. Similarly, the Freundlich model assumes that adsorption occurs on a heterogeneous surface due to the diversity of the adsorption sites or the diverse nature of the sorbate molecule. The linear form of Freundlich isotherm model is,

$$
\log Q_{e}=\log K_{f}+1 / n\left(\log C_{e}\right)
$$

where Qe is the amount of metals adsorbed per unit weight of the adsorbent $(\mathrm{mg} / \mathrm{g})$, Ce the equilibrium concentration $(\mathrm{mg} / \mathrm{L}), \mathrm{Kf}$ is the measurement of adsorption capacity and $1 / \mathrm{n}$ is the adsorption intensity. The kinetics of ACP biosorption from the aqueous solution onto the substrate was also determined by implementing various kinetic models.

\section{RESULTS AND DISCUSSION}

\section{Isolation of bacteria and screening of effective strain}

Maximum tolerable concentration

A total of nine morphologically distinct bacterial isolates were obtained from both tannery sludge and wetland soil sample. Environmental strains obtained from contaminated areas are known to possess stronger resistant mechanism and diverse metabolic activities. The isolates were screened for their ability to survive at various concentrations of MCP and ACP. Interestingly, the isolates showed more tolerance toward ACP and five isolates were capable of surviving up to $2000 \mathrm{mg} \mathrm{L}^{-1}$ concentration of ACP. The growth of bacterial strains in MSM supplemented with MCP was comparatively less and the MTC was found to be $1250 \mathrm{mg} \mathrm{L}^{-1}$ (Figure 2a).

\section{Biofilm formation}

All nine isolates were tested for their ability to form biofilm. Based on the qualitative analysis by test tube method, isolate 2 and isolate 8 were identified as strong biofilm producers whereas, moderate biofilm formation was observed in case of isolate 6 and 9 (Table 1). In the quantitative analysis, isolate 8 showed maximum biofilm forming capability as compared to the other isolates hence considered to be the effective strain and renamed as VITDAJ8. Though there was an inhibition observed in biofilm formation, supplementation of ACP seemed to have no significant effect on the ability of VITDAJ8 to produce biofilm. However, upon supplementation of MCP a drastic reduction in biofilm formation was noticed (Figure $2 \mathrm{~b}$ ). The intensity of biofilm formed in the presence of ACP was significantly greater than that in presence of MCP, which could be due to the inadequacy of the isolates to withstand various concentrations of MCP and utilize it as carbon source. Biofilm formation is one of the stress adaptation strategies observed in many gram negative bacteria. Some of the most efficient biofilm-forming bacteria such as E. coli, Pseudomonas sp., Enterobacter sp., Cronobacter sp., etc., are recently reported for their involvement in the bioremediation various organic pollutants 
(Edwards and Kjellerup, 2013; Turki et al., 2017; Ramasamy et al., 2017).

\section{Extraction and quantification of EPS}

VITDAJ8 was also capable of producing EPS efficiently in NB medium. Presence of ACP in the media did not cause any significant change in EPS production as compared to that of the media without supplementation of pesticides. Therefore the results were in correlation with the data obtained for the formation of biofilm as both the traits act in association with each other. Fascinatingly, a drastic reduction in the concentration of EPS was noticed in the media supplemented with MCP (Figure 2c). This confirms the inability of bacterial cells to retain their innate physiological and metabolic properties in the presence of MCP. In contrast to our findings, Jaiswal et al. (2019) reported the increment of bacterial EPS production with an increase in the concentrations of selected OP insecticides. EPSs play a crucial role in cellular physiology, especially in the aggregation of bacterial cells, flocculation and biofilm formation, cell-cell adhesion and to avoid desiccation and also act as protective barriers (Tian, 2008). Furthermore, Naik et al. in 2012 reported enhanced EPS production by an E. cloacae strain under lead-contaminated condition. Gupta et al. (2019) have also recently reported the significance of EPS in maintaining the integrity of the bacterial cells during pesticide stress.

\section{Identification of effective strain}

VITDAJ8 appeared as small, round, cream colored elevated colonies on MSM agar. It was a gram-negative, rod-shaped and motile bacterium. The biochemical characteristics of the isolate are provided in Table 1. The molecular characterization by $16 \mathrm{~S}$ rRNA gene sequencing and phylogenetic analysis revealed the isolate to be the closest neighbor of Enterobacter cloacae (Accession no.-KP305912) (Figure 3). Similar morphological and biochemical characteristics were described for a plant growth-promoting Enterobacter cloacae subsp. dissolvens MDSR9 isolated from soybean rhizosphere (Ramesh et al., 2014). Enterobacter sp. is one of the predominant groups of bacteria found in the soil rich in organic contents such as rhizosphere and contaminated sites. Due to diverse metabolic activities, various strains of E. cloacae have been taken into account for bioremediation of a wide range of organic pollutants such as hydrocarbons, pesticides, etc., (Ramasamy et al., 2017; Mohanty and Jena, 2018; Das et al., 2017)

(a)

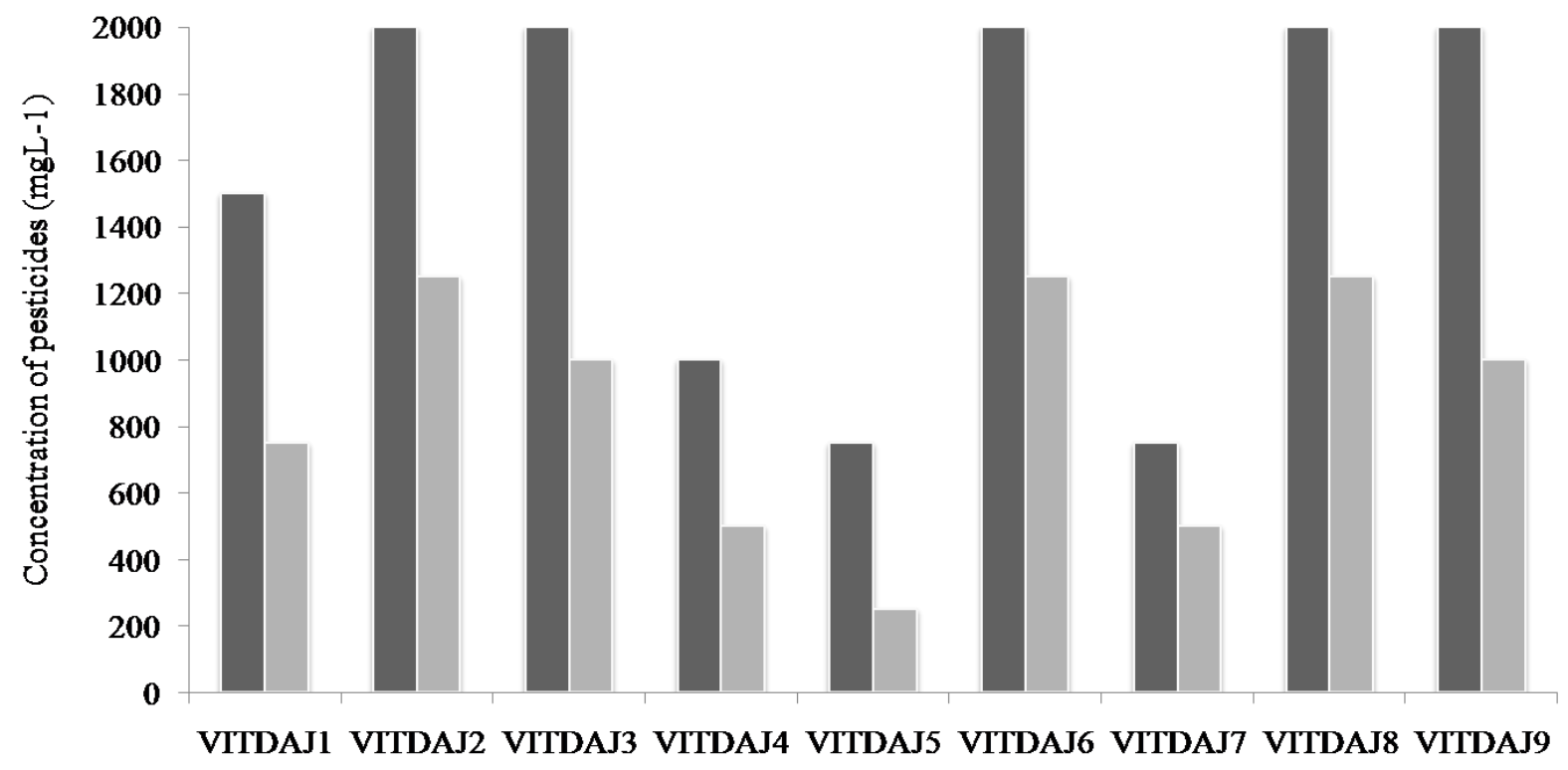

Isolates 

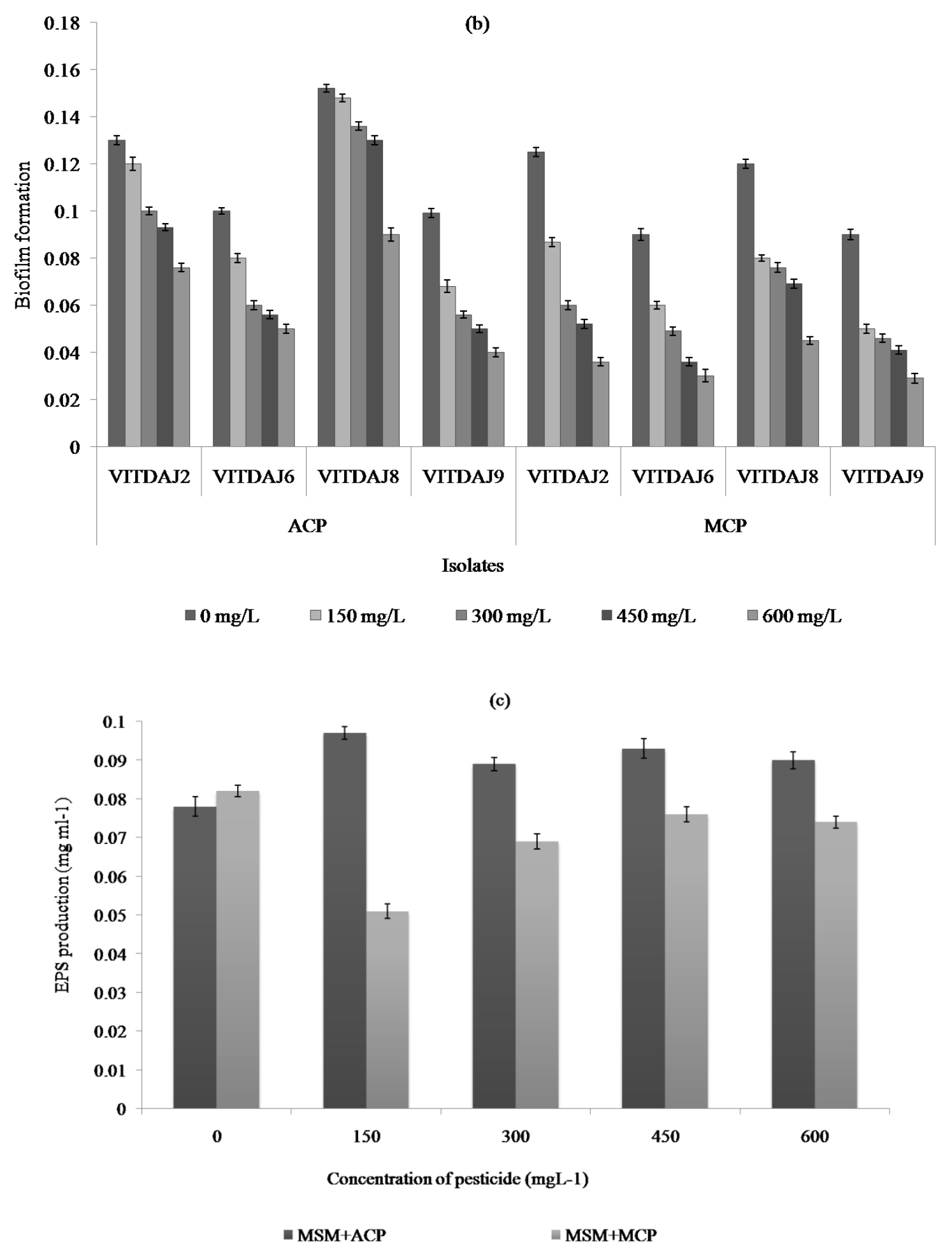

Figure 2. Screening for the effective strain (a) MTC assay showing the tolerance of bacteria against MCP and ACP (b) biofilm formation at various concentrations of pesticides in 96-well microtiter plate and (c) EPS production by the effective isolate VITDAJ8. 
Table 1. Characterization of bacteria.

\begin{tabular}{cccccccccc}
\hline Isolates & Indole & MR & VP & TSI & $\begin{array}{c}\text { Citrate } \\
\text { utilization }\end{array}$ & Oxidase & Catalase & Motility & $\begin{array}{c}\text { Biofilm } \\
\text { (in test tube) }\end{array}$ \\
\hline Isolate 1 & - & + & - & $\mathrm{a} / \mathrm{a}$ & - & + & - & Non- motile & - \\
Isolate 2 & - & + & - & $\mathrm{a} / \mathrm{a}$ & - & + & & Motile & +++ \\
Isolate 3 & - & + & - & $\mathrm{a} / \mathrm{a}$ & - & + & - & Non- motile & + \\
Isolate 4 & - & + & - & $\mathrm{a} / \mathrm{a}$ & - & + & + & Motile & + \\
Isolate 5 & - & + & - & $\mathrm{a} / \mathrm{a}$ & - & + & + & Non- motile & - \\
Isolate 6 & - & + & - & $\mathrm{a} / \mathrm{a}$ & - & + & + & Motile & ++ \\
Isolate 7 & - & + & - & $\mathrm{a} / \mathrm{a}$ & - & + & - & Non- motile & - \\
Isolate 8 & - & + & - & $\mathrm{a} / \mathrm{a}$ & - & + & - & Motile & +++ \\
Isolate 9 & - & - & - & $\mathrm{k} / \mathrm{k}$ & + & + & + & Motile & ++
\end{tabular}

' $\mathrm{a} / \mathrm{a}$ ': acidic end-products and ' $\mathrm{k} / \mathrm{k}$ ': alkaline end-products in TSI test

' +++ ': strong, ' ++ ': moderate, ' + ' weak and ' - ': negative in biofilm formation

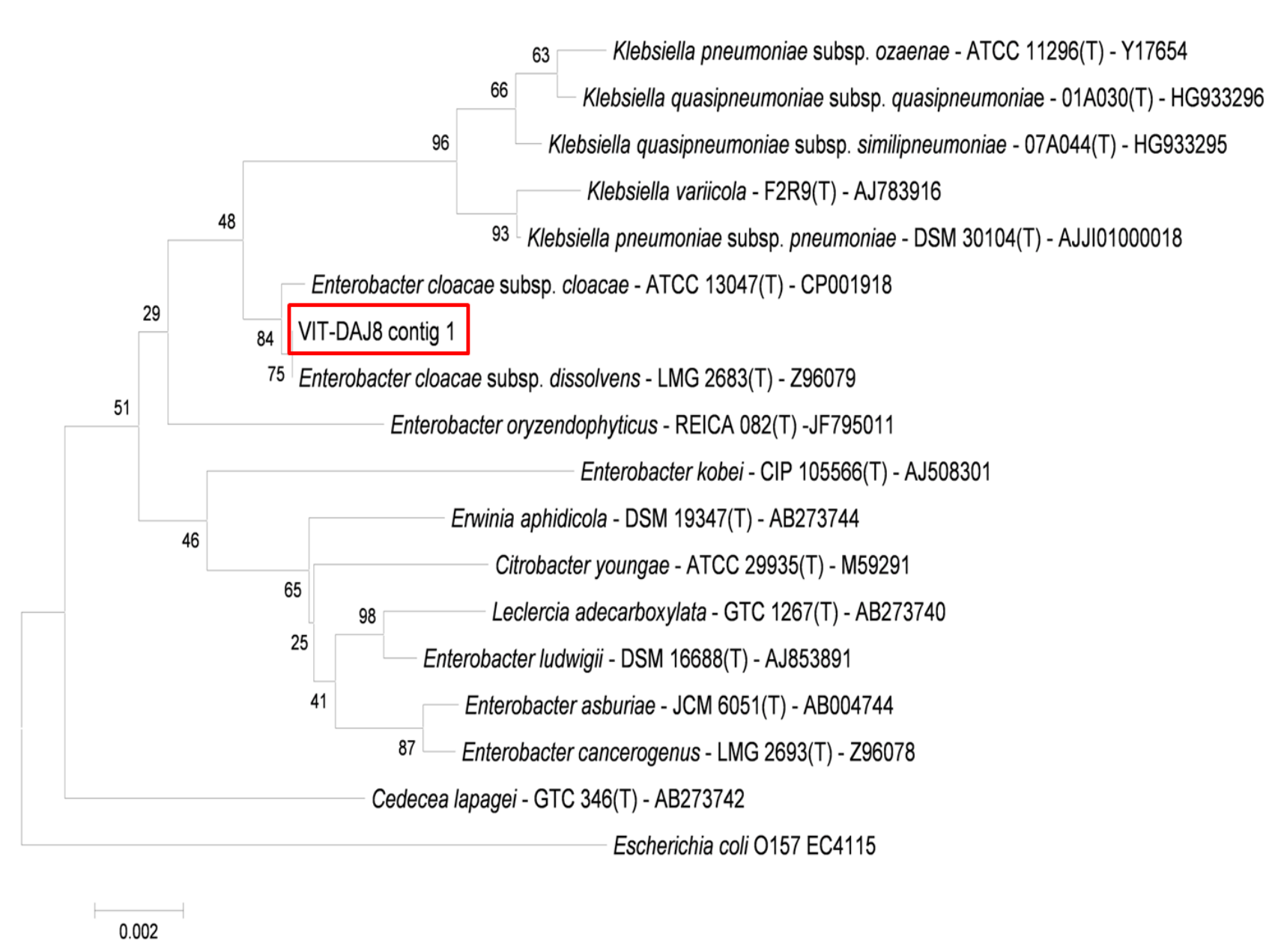

Figure 3. Identification of VITDAJ8 by phylogenetic tree analysis. 


\section{Bioremoval of $A C P$ in vertical packed bed biofilm bioreactor}

VITDAJ8 strain formed an efficient amount of biofilm on the groundnut shell surface which was confirmed by the dilution plate count method. The bioremoval process was dependent on contact time and intensity of bacterial biofilm developed on groundnut shells. Further in the equilibrium adsorption study the adsorption isotherm was represented as the concentration of adsorbate and quantity of pesticide adsorbed. The study fundamentally explained the interactive behavior of solute particles towards the adsorbent. Biosorption of ACP with biofilm support $(86 \%)$ was found to be significantly greater than that of without biofilm (18\%). Continuous reduction in the concentration of ACP was observed in $U V$-Vis spectrophotometer and HPLC analysis and maximum biosorption up to $436 \mathrm{mg} \mathrm{L}^{-1}$ was achieved by biofilm coated groundnut shell with within 90 min of reaction time (Figure 4a). This could be due to the ability of bacterial biofilm in increasing the surface area, surface porosity and developing more binding sites for better adherence of pesticide molecules onto the substrates. As shown in Figure 4b, the amount of acephate adsorbed from the aqueous solution increased with time while, the equilibrium was attained at 70 minutes of contact time at $25 \pm 2{ }^{\circ} \mathrm{C}$ temperature and $6.7 \mathrm{pH}$. The smooth and continuous adsorption plot indicated monolayer distribution of adsorbate on to the biofilm formed on groundnut shell. Further, the adsorption isotherm study of the equilibrium data revealed the biosorption process to be the best fit for Langmuir isotherm model and the regression coefficient $r^{2}$ value 0.966 authenticated the accuracy of the data presented (Figure 4c). Promising results in the approach of waste water treatment using various biofilm bioreactors has been reported and convincing theories on the importance of bacterial biofilm in waste removal has been established by Edwards and Kjellerup (2013), Chen et al. (2007) and Turki et al. (2017). Pani et al. (2017) in a similar study also reported efficient bioremoval of selected heavy metals using biofilm formed by Pseudomonas sp. Dash and Osborne (2020) reported effective biofilm based bioremoval of two OP pesticide profenofos $(96 \%)$ and quinalphos (92\%) within 120 min using a similar VFPBB bioreactor. Rodríguez-Castillo et al. (2020) reported reactor scale treatment of neonicotinoid insecticide mixture using effective bacterial consortia in a stir tank bioreactor system (STBR) and eliminated $95.8 \%$ of total insecticide. In another study Azizi et al. (2020) reported efficient bioremoval of diazinon up to $97.66 \%$ from synthetic waste water using moving bed biofilm reactor (MBBR) which was indicated as a second order kinetic reaction.

The linear plot 1/C against time in Figure 4d depicts ACP biosorption as second-order kinetic reaction with an $r^{2}$ value of 0.99 . Therefore, the kinetic data characterized the adsorption of acephate as a two-step process which are possibly adsorption and diffusion. Diffusion is a simultaneous process that occurs during adsoption where the particle of interest moves from the bulk of solution towards the adsorbent surface. In addition to the superficial diffusion there is relative possibility intraparticle diffusion from the surface into the pores of the adsorbent material. In our study the presence of catabolic enzymes synthesized by the biofilm matrix has induces the possibility of diffusion via enzymatic degradation of acephate. Shankar et al. (2020) in a recent study reported similar kinetic properties for the removal of pentachlorophenol pesticide from aqueous solutions using modified chitosan. Despite all the success there is very limited research conducted in biofilm based bioremoval of OP pesticides. 


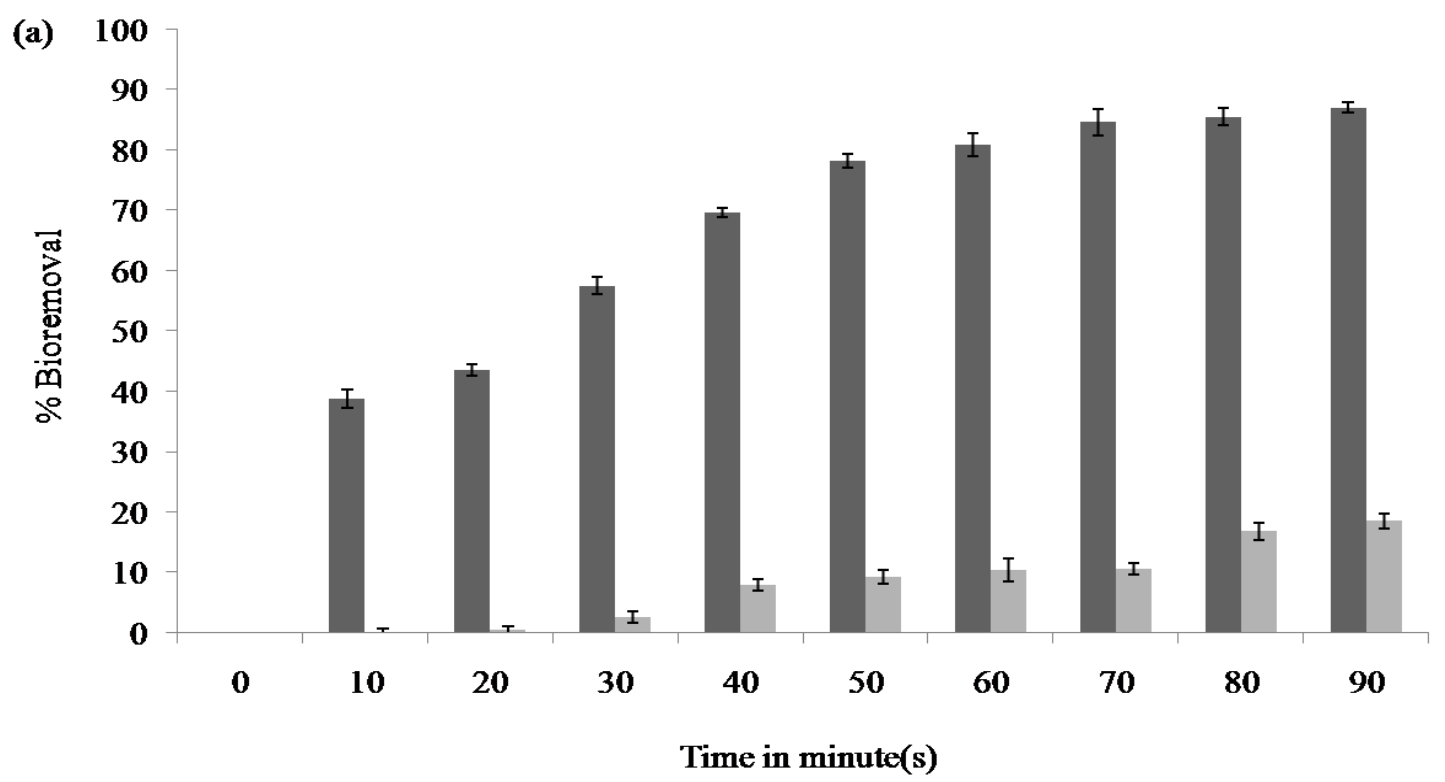

— With biofilm

Without biofilm

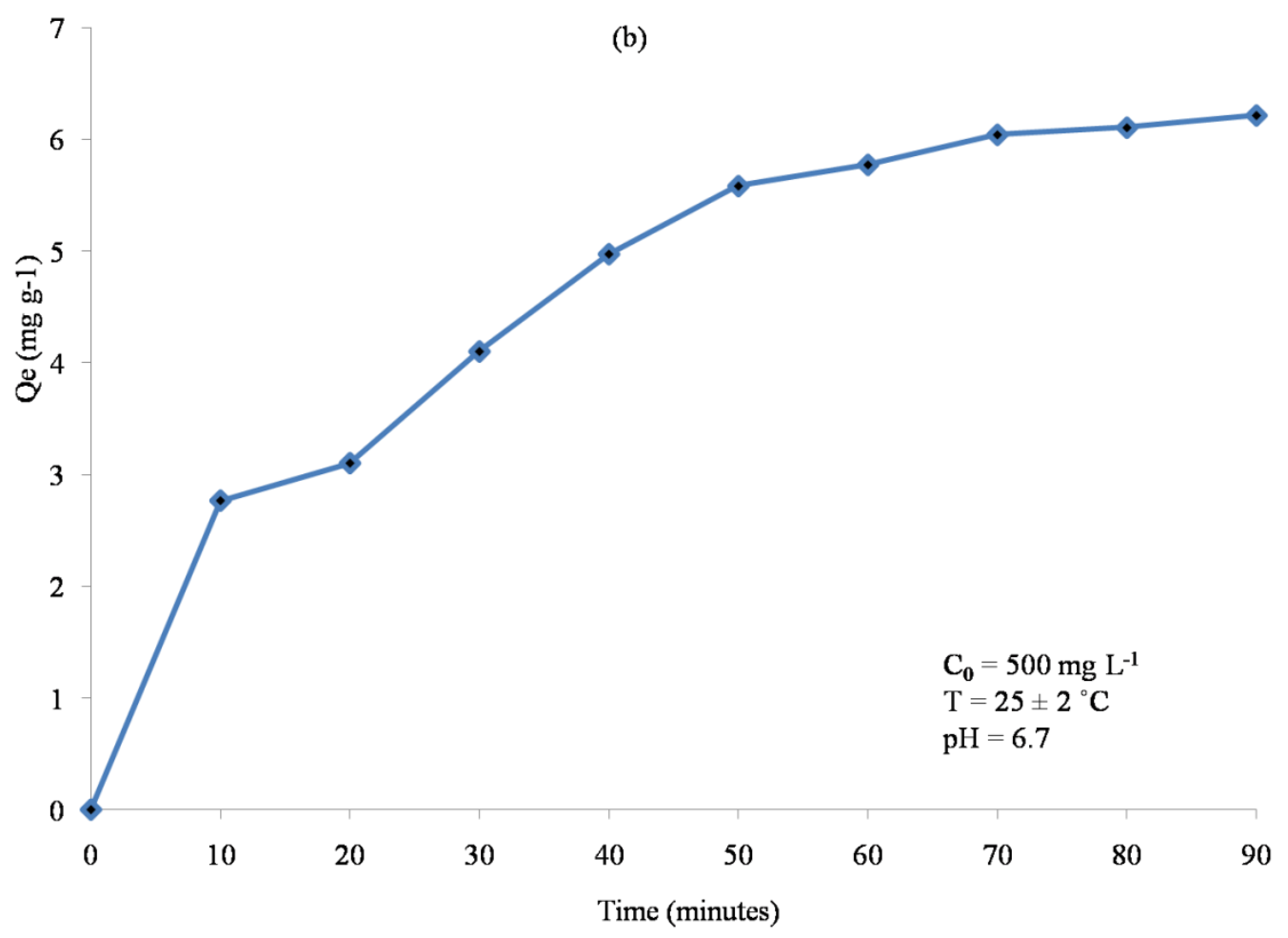


(c)

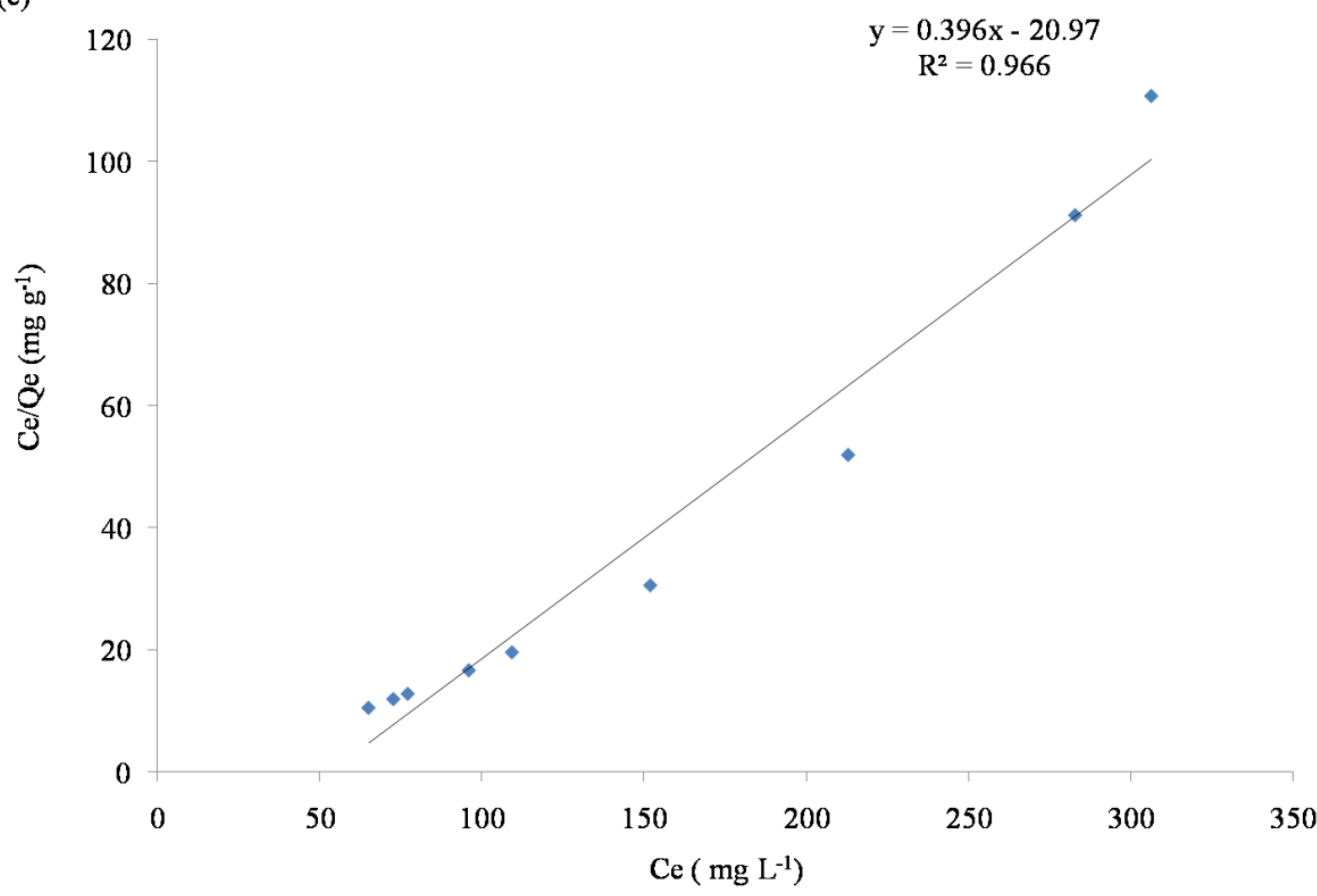

(d)

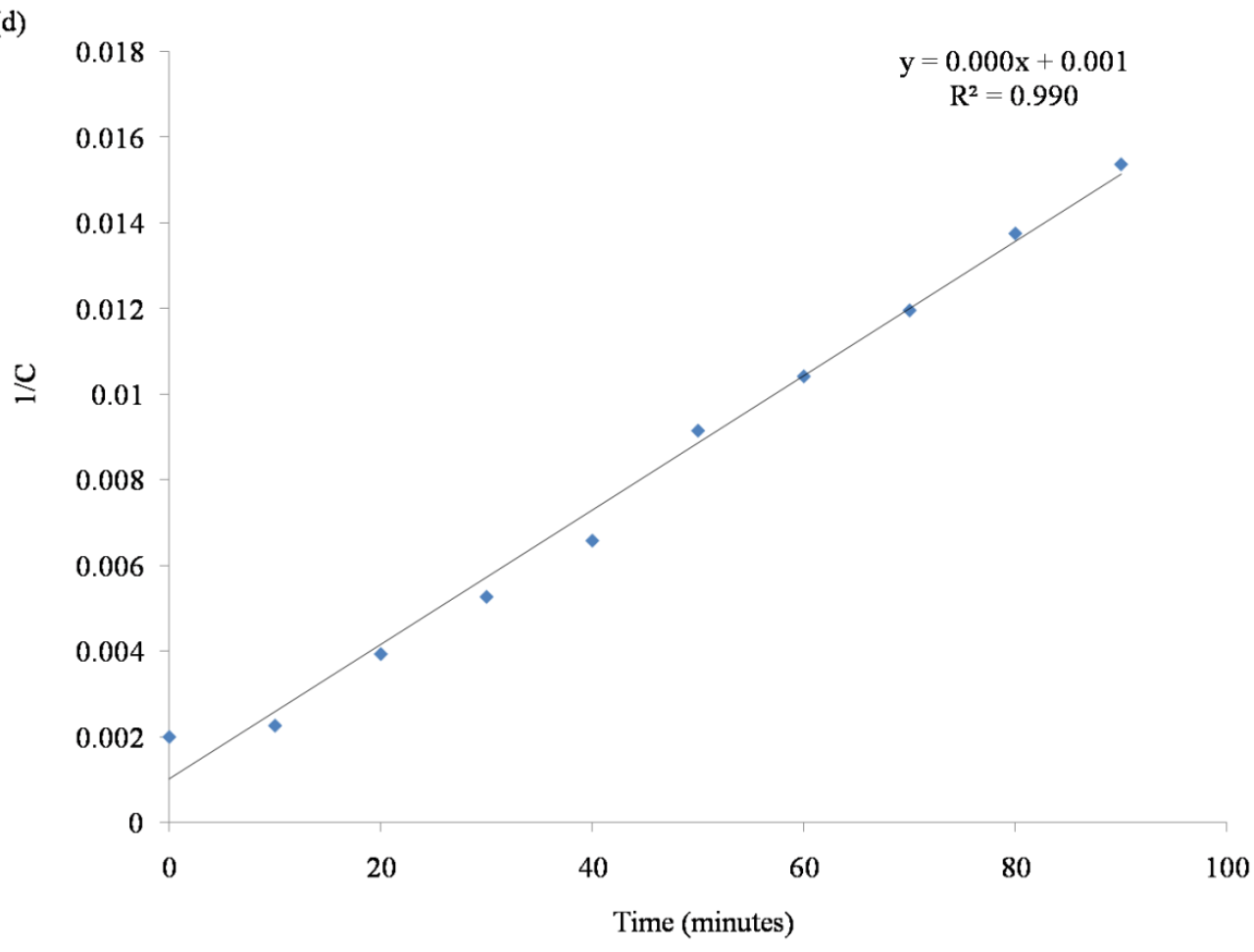

Figure 4. Biofilm-based bioremoval of ACP. (a) \% bioremoval of ACP with and without biofilm, (b) Equilibrium time for adsorption of acephate onto the surface biofilm; (c) Langmuir plot showing adsorption isotherm of acephate and (d) second-order kinetic modeling for ACP biosorption 


\section{CONCLUSION}

The isolate VITDAJ8 was a high pesticide tolerant and efficient biofilm forming bacteria capable of removing ACP insecticide from aqueous solution. Based on 16S rRNA gene sequencing VITDAJ8 was identified to be the closest neighbour of Enterobacter cloacae. The vertical packed bed bioreactor designed for the study worked efficiently in the bioremoval of ACP. Development of bacterial biofilm could significantly enhance the adsorptive properties of groundnut shell which led to an enhanced biosorption process. Maximum biosorption up to $86 \%$ was achieved within 90 min of reaction time and the experimental data fitted well with the second-order kinetic model. The equilibrium data was found to be the best fit for the Langmuir adsorption isotherm model. The study paved a way for the possible development of a successful biofiltration system for the treatment of water contaminated with OP pesticides and other organic chemicals. However, a thorough research on the kinetics and thermodynamic aspects of the biosorption process need to be conducted.

\section{ACKNOWLEDGEMENTS}

The authors would like to acknowledge the Vellore Institute of Technology for providing the infrastructure and laboratory facilities to carry out the research work. The authors extend their gratitude to VIT-TBI (Technology Business Incubator) for providing instrumentation facilities to conduct analytical studies.

\section{REFERENCES}

Aimer, Y., Benali, O., \& Serrano, K. G. 2019. Study of the degradation of an organophosphorus pesticide using electrogenerated hydroxyl radicals or heat-activated persulfate. Separation and Purification Tecbnology 208:27-33.

Aimer, Y., Benali, O., Salghi, R., Latapie, L., \& Serrano, K. 2017. Removal of pesticides by electrochemical oxidation using a boron doped diamond anode. Material and Environmental Science 8(3): 777-83.

Azizi, A., Dargahi, A. \& Almasi, A. 2019. Biological removal of diazinon in a moving bed biofilm reactor-process optimization with central composite design. Toxin Reviews: $1-11$.

Bhalerao, T. S., \& Puranik, P. R. 2007. Biodegradation of organochlorine pesticide, endosulfan, by a fungal soil isolate, Aspergillus niger. International Biodeterioration \& Biodegradation 59(4): 315-321.

Breugelmans, P., Horemans, B., Hofkens, J., \& Springael, D. 2010. Response to mixed substrate feeds of the structure and activity of a linuron-degrading triple-species biofilm. Research in Microbiology 161(8): 660-666.

Cappuccino, J. G. \& Sherman, N. 1992 Biochemical activities of microorganisms. In: Microbiology, a laboratory manual, 1st edition, pp. 105-300. The Benjamin/Cummings Publishing Co, California,

Chandran, P., \& Das, N. 2011. Degradation of diesel oil by immobilized Candida tropicalis and biofilm formed on gravels. Biodegradation 22(6): 1181-1189.

Chen, S., Sun, D., \& Chung, J. S. 2007. Treatment of pesticide wastewater by moving-bed biofilm reactor combined with Fenton-coagulation pretreatment. Journal of Hazardous Materials 144(1-2): 577-584.

Christensen, G. D., Simpson, W. A., Younger, J. J., et al. 1985. Adherence of coagulase-negative staphylococci to plastic tissue culture plates: a quantitative model for the adherence of Staphylococci to medical devices. Journal of Clinical Microbiology 22(6): 996-1006.

Das, A., Belgaonkar, P., Raman, A. S., Banu, S., \& Osborne, J. W. 2017. Bioremoval of lead using Pennisetum purpureum augmented with Enterobacter cloacae-VITPASJ1: A pot culture approach. Environmental Science and Pollution Research 24(18): 15444-15453.

De Lipthay, J. R., Tuxen, N., Johnsen, K., Hansen, L. H., Albrechtsen, H. J., Bjerg, P. L., \& Aamand, J. 2003. In situ exposure to low herbicide concentrations affects microbial population composition and catabolic gene frequency in an aerobic shallow aquifer. Applied and Environmental Microbiology 69(1): 461-467.

De Rossi, B. P., Calenda, M., Vay, C., \& Franco, M. 2007. Biofilm formation by Stenotrophomonas maltophilia isolates from device-associated nosocomial infections. Revista Argentina de Microbiologia 39(4): 204-212.

Edwards, S. J., \& Kjellerup, B. V. 2013. Applications of biofilms in bioremediation and biotransformation of persistent organic pollutants, pharmaceuticals/personal care products, and heavy metals. Applied Microbiology and Biotechnology 97(23): 9909-9921.

Gupta, J., Rathour, R., Singh, R., \& Thakur, I. S. 2019. Production and characterization of extracellular polymeric substances (EPS) generated by a carbofuran degrading strain Cupriavidus sp. ISTL7. Bioresource Tecbnology 282: 417-424.

Jaiswal, D. K., Verma, J. P., Krishna, R., Gaurav, A. K., \& Yadav, J. 2019 Molecular characterization of monocrotophos and chlorpyrifos tolerant bacterial strain for enhancing seed germination of vegetable crops. Chemosphere 223:636-650.

Mohanty, S. S., \& Jena, H. M. 2018. Process optimization of butachlor bioremediation by Enterobacter cloacae using Plackett Burman design and response surface methodology. Process Safety and Environmental Protection 119: 198-206.

Naik, M. M., Pandey, A., \& Dubey, S. K. 2012. Biological characterization of lead-enhanced exopolysaccharide produced by a lead resistant Enterobacter cloacae strain P2B. Biodegradation 23(5): 775-783.

Pani, T., Das, A., \& Osborne, J. W. 2017. Bioremoval of zinc and manganese by bacterial biofilm: A bioreactor-based approach. Journal of Photochemistry and Photobiology B: Biology 175: $211-218$

Petsas, A. S., \& Vagi, M. C. 2018. Photocatalytic degradation of selected organophosphorus pesticides using titanium 
dioxide and UV Light. Titanium Dioxide: Material for a Sustainable Environment 241.

Ramasamy, S., Arumugam, A., \& Chandran, P. 2017. Optimization of Enterobacter cloacae (KU923381) for diesel oil degradation using response surface methodology (RSM). Journal of Microbiology 55(2): 104-111.

Ramesh, A., Sharma, S. K., Sharma, M. P., Yadav, N., \& Joshi, O. P. 2014. Plant growth-promoting traits in Enterobacter cloacae subsp. dissolvens MDSR9 isolated from soybean rhizosphere and its impact on growth and nutrition of soybean and wheat upon inoculation. Agricultural Research 3(1): 53-66

Rodríguez-Castillo, G., Molina-Rodríguez, M., CambroneroHeinrichs, J. C. et al. 2019. Simultaneous removal of neonicotinoid insecticides by a microbial degrading consortium: Detoxification at reactor scale. Chemosphere 235: 1097-1106.

Shankar, A., Kongot, M., Saini, V. K., \& Kumar, A. 2020. Removal of pentachlorophenol pesticide from aqueous solutions using modified chitosan. Arabian Journal of Chemistry 13(1): 1821-1830.

Singh, B. K., \& Walker, A. 2006. Microbial degradation of organophosphorus compounds. FEMS Microbiology Reviens 30(3): 428-471.

Singh, R., Paul, D., \& Jain, R. K. 2006. Biofilms: implications in bioremediation. Trends in Microbiology 14(9): 389-397.

Sintuya, P., Narkprasom, K., Jaturonglumlert, S., Whangchai, N., Peng-Ont, D., et al. 2018. Effect of gaseous ozone fumigation on organophosphate pesticide degradation of dried chilies. Orone: Science \& Engineering 40(6): 473-481.

Tamura, K., Dudley, J., Nei, M., \& Kumar, S. 2007. MEGA4: molecular evolutionary genetics analysis (MEGA) software version 4.0. Molecular Biology and Evolution 24(8): 1596-1599.

Tian, Y. 2008. Behaviour of bacterial extracellular polymeric substances from activated sludge: a review. International Journal of Environment and Pollution 32(1): 78-89.

Toptas, A., Demierege, S., Mavioglu Ayan, E., \& Yanik, J. 2014. Spent mushroom compost as biosorbent for dye biosorption. CLEAN-Soil, Air, Water 42(12): 1721-1728.

Turki, Y., Mehri, I., Lajnef, R., Rejab, A. B., Khessairi, et al. 2017. Biofilms in bioremediation and wastewater treatment: characterization of bacterial community structure and diversity during seasons in municipal wastewater treatment process. Environmental Science and Pollution Research 24(4): 3519-3530.

Vimala, R., \& Das, N. 2009. Biosorption of cadmium (II) and lead (II) from aqueous solutions using mushrooms: a comparative study. Journal of Hazardous Materials 168(1): 376382.

Yedla, S., \& Dikshit, A. K. 2008. Removal of endosulfan from water using wood charcoal-Adsorption and desorption. Journal of Environmental Engineering 134(2): 102-109. 